\title{
Social media mixed with news in political candidate judgment: Order effects on knowledge and affect
}

\author{
Scott P. Robertson ${ }^{\mathrm{a}, *}$, Bryan Semaan ${ }^{\mathrm{b}}$, Sara Douglas ${ }^{\mathrm{c}}$ and Misa Maruyama ${ }^{\mathrm{c}}$ \\ ${ }^{a}$ Information and Computer Sciences Department, University of Hawaii at Manoa, Honolulu, HI, USA \\ ${ }^{\mathrm{b}}$ School of Information Studies, Syracuse University, Syracuse, NY, USA \\ ${ }^{\mathrm{c}}$ Communication and Information Sciences Program, University of Hawaii at Manoa, Honolulu, HI, \\ USA
}

\begin{abstract}
In the context of politics, emotions and facts work together to shape opinions about political candidates. While there is considerable research on motivated reasoning about political issues, there is less attention to how affect and rationality combine in the hybrid world of new media. This study examined the interaction of social media comments about politicians with more traditional information sources. Participants were exposed to political candidates' Facebook news feeds, to news articles about the candidates, and to a political speech. The order of exposure was varied and measures of both knowledge and emotion were taken. When social media was encountered before news about a political candidate, it influenced feelings toward the candidate but did not influence personal mood or perceived knowledge. In contrast, when social media was encountered before information unrelated to the candidates, it negatively influenced all dependent measures. The findings are discussed in terms of motivated reasoning theories, Papacharissi's concept of "affective publics," and the implications for civic participation in the new media era.
\end{abstract}

Keywords: Social media, media hybridity, motivated reasoning, affective publics, e-Participation, e-Democracy, online public sphere

\section{Introduction}

\subsection{Social media and civic participation}

Political discourse has been studied in several types of social media situations, including political blogs [10,83,86,92], discussion forums [57], online videos [17,50] and social networking sites (SNSs) like Facebook $[6,35,65,66,68,70,93]$. There is considerable discussion about how computer-mediated political discussion might serve as an online "public sphere" in the sense that Habermas [21] described it as an open forum for the rational discussion of diverse views [10,53,54], with considerable attention being paid to whether SNSs narrow or widen political discourse [3,18,28,46,74,78-81,87]. More recently, media theorists and sociotechnical researchers have turned their attention to what has been called

\footnotetext{
${ }^{*}$ Corresponding author: Scott P. Robertson, Information and Computer Sciences Department, University of Hawaii at Manoa, 1680 East-West Rd., Honolulu, HI 96822, USA. Tel.: +1 808956 2023; Fax: +1 808956 3548; E-mail: scott.robertson@ hawaii.edu.
}

1570-1255/16/\$35.00 (C) 2016 - IOS Press and the authors. All rights reserved

This article is published online with Open Access and distributed under the terms of the Creative Commons Attribution NonCommercial License (CC BY-NC 4.0). 
the "sprawling" public sphere [11] and the hybrid nature of new media $[6,29,45,46]$. In this paper we examine the influence of exposure to social media content on the interpretation of news and whether the order of encounter matters.

The need to understand how social media and news influence each other is clear from an examination of how news is now encountered. According to the Pew Internet and American Life project, $71 \%$ of all American online adults (58\% of the entire adult population) report that they use Facebook, $23 \%$ of all American online adults (19\% of the entire adult population) report that they use Twitter, and $52 \%$ of internet users say that they visit two or more social media sites regularly [14]. Almost half (47\%) of Facebook users report that they get news from Facebook, usually incidentally and not exclusively [47], and slightly higher percentages get news from Twitter (52\%) and reddit (62\%) [27]. A little more than one third (36\%) of SNS users say that SNSs are important for keeping up with political news in particu$\operatorname{lar}[59]$.

Internet users are more likely than non-Internet users to be involved in civic and political activities such as attending a political rally, trying to influence a vote, and actually voting or reporting intention to vote [22]. Frequent Facebook users are even more engaged in these civic/political activities [22,59]. Facebook users maintain many types of relationships within the SNS and seem to gain and maintain social capital from its use $[15,63,91]$. Several researchers suggest that computer-mediated interactions have positive effects on community engagement and civic involvement $[13,23,32,63,91]$.

\subsection{Hybrid news and information assemblages}

News in general, and political news in particular, is increasingly consumed via multiple platforms with varying levels of legitimacy and filtering. Chadwick and his colleagues $[6,29]$ term current news consumers "omnivores" to stress that they comfortably navigate diverse information sources. This includes a move toward encountering traditional news in online formats mixed together with less traditional information from blogs and social media. In fact, media researchers have found considerable "intermedia agenda setting" [46] as diverse information streams combine both sources of news for mainstream media and hybrid information assemblages [6] for citizen news producers and consumers.

Klinger and Svensson [33] point out that social media now plays a very significant role in the distribution of news and its consumption in hybrid information contexts. The traditional two-step flow model of information dissemination in political news settings, stressing as it does the importance of opinion leaders as filters and interpreters, becomes more complex in hybrid environments [7,51]. Even a "multistep" view [8] is questionable because the unidirectional nature of these theories fails to explain how news consumers may cycle and recycle an information item through different channels for different purposes [88] or how news algorithms might be deployed to aggregate content that would otherwise never come together via purposeful search. This raises many research questions about how different types of political information - news, expert opinion, non-expert points of view, direct candidate statements and so on - mix as they are routinely encountered together.

The longstanding two-step and multistep flow models of information dissemination via mass media [31] stress that media serves a gatekeeping role since traditional media outlets select what stories to pass through and how to contextualize those stories. Recent studies have shown that social media can play this role [9,25], although Bennet and Manheim [1] point out that traditional opinion leaders may be playing a less important role in the fragmented hybrid media environment of the internet, and Weeks, Ardèvol-Abreu and Gil de Zúñiga [89] describe the increasingly important role of "prosumers," or highly active social media users who play a role of filtering and news transmission to others. In 
the social-media era, many news stories are passed on to others via friendship networks with varying goals [38] that are not necessarily aligned with what traditional media considers newsworthy, with the maintenance of social capital being one predominant goal $[19,56]$.

\subsection{Rationality and affect}

Emotion is an important part of social media activity. Emotionally charged tweets are more likely to be shared than neutral tweets [78] and social media sentiment has been studied in response to, and as a predictor of, many phenomena ranging from stock market trends [5] to elections [84] and more [4]. Papacharisi and de Fatima Oliveira [55] have claimed that news, opinion, and emotion are so intermingled in contemporary networked environments that they are essentially indistinguishable and should be understood as a new kind of "affective news" [52], that is to say news which is contextualized within a dialog rich in emotional content. The advent of hybrid news environments with significant affective content suggests a need to understand how affect and information intermingle and influence each other $[6,52,85]$.

The idea of virtual social networks as a new kind of public sphere has been discussed and critiqued extensively. The public sphere, as Habermas [21] originally framed it, is a space in which diverse actors can meet to discuss common interests, especially those of a civic nature. As Papacharissi [53] and others $[16,39]$ have pointed out, however, the Habermasian public sphere privileges rational deliberation whereas many studies of political discourse suggest instead that emotion and rationality work together in important ways. Rational-actor models dominated theories of political decision making for many decades [64]. These models posit that decision makers gather information, weigh choices, and engage in reasoning about costs and benefits of various decisions. However, such models have been challenged by theorists and researchers coming from psychology and other behavioral social sciences $[37,76]$, political sciences $[34,42,58,60,61]$, and media researchers $[6,52,82]$. A prevailing view now is that people utilize "motivated reasoning" in political decision making $[26,34,42,58,60,61]$ where affect and emotion play a role in deciding about whether information is important, how it should be interpreted, and how it is ultimately remembered.

One challenge involves the pragmatics of making complex decisions that require significant cognitive resources. Lau [37] suggests that people are capable of estimating the cognitive effort required to make complex decisions and that they are often unmotivated to expend such effort when they can instead satisfice by using short-cut heuristics. This view falls into a broader category of bounded rationality theories $[24,30,75,77]$ in which actors weigh the complexity of a problem against cognitive and other resources. A popular, heuristic-based theory in political psychology is the "on-line running tally" idea $[40,41,60]$. In this model, people create an initial, schema-based concept of a candidate which they then use as a comparator when new information is encountered. New information is judged by how it affects the candidate schema and used to update the schema as necessary, but the actual information used for updating might be forgotten. Rahn [58] proposes that affective cues serve as an important source of information about the importance of political facts, and indeed other researchers have found that emotional content, both positive and negative, increases the likelihood of information being shared in social media $[2,26,78]$.

Both social psychologists and political scientists have spent considerable effort studying the role of emotion in the political arena $[20,34,43,58,60,62]$. Marcus et al. [44] propose that political judgment is a balance between habit and reason that is mediated by emotion. Studies of the impact of media on decision making have also emphasized the role of impression formation and manipulation in forming political 
judgments [94]. Information gleaned from prior material has a priming effect on later material [40] and provides a frame in which subsequent material is interpreted [72]. Both of these influences can operate on both a cognitive level, for example influencing what people think is salient, and on an affective level, for example influencing whether people feel good, neutral, or bad about an issue [48]. Some researchers feel that cognition and affect work together in political media to influence what people feel is important, and that highly salient issues with negative valence are judged to be most important [71]. There is some evidence that news delivered with a positive tone made people feel that it was less important $[71,73]$.

While non-opinion traditional media is often written in a neutral style, there is no such control over the style of information in social media. Indeed, the multiple participants/authors of social media have many goals $[12,36]$ and in the context of political discourse they often seek explicitly to influence others and the emotional tone of the content can be positive and negative $[65,66]$. Taken together, the use of heuristic shortcuts, the influence of emotional content, and the existence of framing effects all suggest that decision making in the "sprawling" public sphere [11] will be highly complex. In this study, we explore both rational and affective components of political candidate choice when multiple news materials were influencing each other.

\subsection{Study rationale and research questions}

Many studies of computer-mediated political activity focus on a single context or application such as Twitter or Facebook. However, in real life people encounter information about politics in a variety of forms and utilize multiple online tools to navigate and experience political events $[45,74]$ in what Dahlgren [11] refers to as the "sprawling" public sphere. Papacharissi [53] suggests that citizens today encounter civic society as a hybrid environment of overlapping private and public spheres and that citizenship itself is experienced in a highly fluid manner. She suggests that "affective news" is a new kind of media environment in which information and emotion intermingle to generate "affective attunement" and create "affective publics" that are connected in discursive networks [52]. In this study, we explore how different types of media influence each other, and specifically how social media interacts with other media such as online news articles. We focus on social media's potential effects on knowledge and emotional state.

In this study we gave participants a collection of different online materials to read. We focused on the question of whether and how social media, specifically Facebook posts about political candidates, might interact with news articles about those candidates. In order to study this question, we varied the order in which subjects read the same materials. In some conditions they read social media followed by news articles, and in other conditions they read news articles followed by social media. As a "neutral" contrast, we also included conditions in which subjects read the same social media materials together with a political speech that had nothing to do with the election. The order of presentation of the social network materials and the speech was varied in the same way. We took measures of knowledge and affect (both personal affect and feelings toward the candidates) with the goal of understanding how social media content might influence both. We are not manipulating the valence (positive/negative) of the social media content, but rather examining the impact of order in which this material is encountered vis-à-vis less affectively laden information.

Our research questions were as follows:

RQ1: Does social media order influence perceived knowledge? A social media inquiry amplification effect would occur if the interactive and often combative nature social media creates an interest in the race such that subjects feel more informed when they subsequently read informative 
Table 1

Demographic information about the participants

\begin{tabular}{lccc}
\hline Scale & Min & Max & Mean \\
\hline Political views & 1 & 5 & 2.80 \\
Interest in politics & 1 & 4 & 2.58 \\
Likelihood of voting & 1 & 5 & 3.27 \\
Familiarity with ICSs & 1 & 5 & 4.18 \\
SNS usage & 1 & 5 & 1.78 \\
E-mail usage & 1 & 4 & 1.67 \\
Texting and IM & 1 & 2 & 1.11 \\
\hline
\end{tabular}

Note. Scale endpoints are described in the text.

material in contrast to when they read informative material first followed by social media. A social media inquiry suppression effect would occur if the nature of social media puts people off and makes them less interested in subsequent material, leading to the opposite pattern.

RQ2: Does social media order influence feelings about the candidates? A social media affect amplification effect would occur if the interactive and often combative nature of social media creates a higher state of arousal that is amplified by subsequent informative material and results in higher affect measures when social media comes first in contrast to when it comes last. A social media affect depression effect would occur if social media about politics leads to negative feelings and lower affect measures, leading to the opposite pattern

RQ3: Does social media order influence personal feelings? A social media personal affect amplification effect and a personal affect depression effect mirror the predictions from RQ2, except that their effects would be assessed by measures of personal affect.

\section{Method}

\subsection{Participants}

Forty-five undergraduate students, 23 males and 21 females (one non-response), from a state university participated in this study. The students were solicited as part of an optional course participation opportunity.

Thirty-seven of the participants reported that they were in the 18-20 year-old age category and seven subjects reported that they were in the 21-29 year-old age category (one non-response). The sample contained 16 participants who identified themselves as Democrats, 22 who identified themselves as Independents, and 6 who identified themselves as Republicans (one non-response). Table 1 shows means, minimums, and maximums for ratings measuring political ideology and technology use. The relevant scale endpoints are as follows: Political Views $(1=$ Very Liberal, $5=$ Very Conservative); Interest in Politics, Likelihood of Voting, and Familiarity with ICTs ( $1=$ Very Low, $5=$ Very High); SNS Usage, Email Usage, and Text/IM Usage ( $1=$ Very Frequent, $5=$ Very Infrequent). Taken together, the data suggest that these participants were distributed along the political spectrum and had high familiarity with ICTs and social networking. They had a moderate interest in politics and little experience in elections.

\subsection{Materials}

The social media materials comprised over 700 consecutive posts and their related comments copied from each of the Facebook walls of the two candidates for Governor of Mississippi in 2011: Republican candidate Phil Bryant ( $\sim 500$ posts) and Democratic candidate Johnny DuPree ( 300 posts). The 


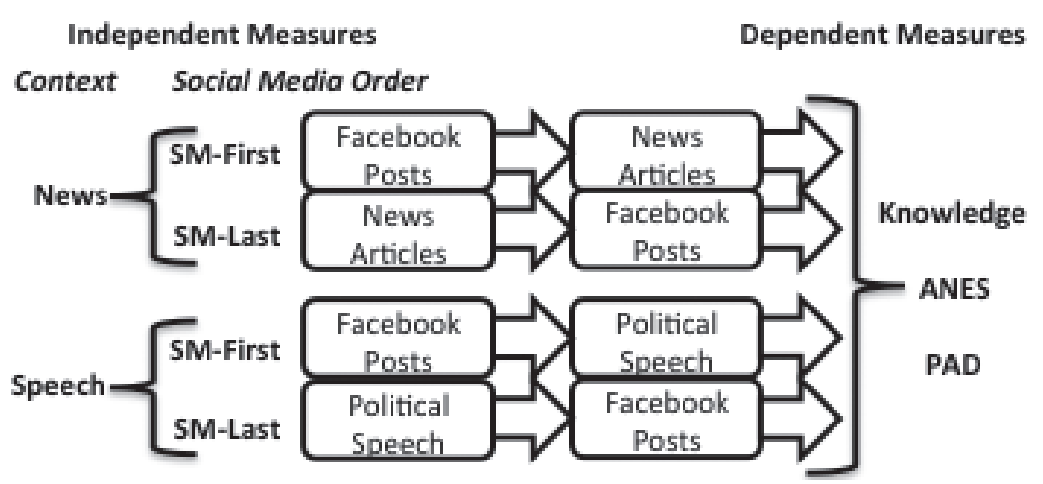

Fig. 1. Experimental design. Participants saw social media (Facebook posts) either before (SM-First) or after (SM-Last) other materials, which consisted of either campaign-relevant news stories (News) or a campaign-irrelevant political speech (Speech).

Mississippi gubernatorial election was selected for several reasons. First, it was one of only four gubernatorial elections held in 2011, and there was a reasonable chance our subject pool (located in a different region of the United States) would have little or no prior knowledge of the candidates. Post-experiment interviews confirmed that this was the case. Second, Mississippi's election was the only gubernatorial race in 2011 without an incumbent candidate, so the assumption was that media coverage would be more even across the candidates. Finally, both Bryant and Dupree maintained active Facebook pages that attracted numerous comments by citizens.

Posts were collected from the four months immediately preceding the election (August 5, 2011November 8, 2011). Posts were taken from the candidates' public walls, which contained the top-level posts of the candidates followed by comments from Facebook users. These materials were presented to subjects in a browser exactly as they appeared within the Facebook application.

The news articles consisted of the text of three articles from online media sources about the candidates. Two were Associated Press stories (Elliot, J., Jr. "Mississippi Governor Race: Phil Bryant, Johnny DuPree debate." Djounal.com Northeast Mississippi News. Oct 11, 2011; and Pettus, E. DuPree, "Bryant back Initiative 26 before Nov." Starkville Daily News. Oct. 23, 2011) and one was from a local news source (Soroka, B. DuPree, Bryant Talk Campaign Cash. WJTV News Channel 12, Oct. 27, 2011). Combined, they comprised just more than three pages.

The articles were selected because they provided balanced coverage of the candidates. To check the distribution of news coverage between candidates, each sentence was categorized according to whether it was about Bryant, DuPree, or someone or something else. The number of words about each candidate relative to the total number of words in each article was calculated. Overall, the total number of words dedicated to discussing each candidate was fairly even across the three articles: 35 percent of the words were about DuPree, and 31 percent were about Bryant.

The political speech was a 2900-word final address delivered by then-Governor Haley Barbour on Jan. 11, 2012 to the state legislature of Mississippi (http://www.governorbarbour.com/news/2011/dec/1.4 barbourfinaladdress.html). It has political content relevant to the state of Mississippi but does not address the campaign or the candidates.

\subsection{Design}

The experimental design was a $2 \times 2$ independent groups design as depicted in Fig. 1. Subjects were assigned randomly to one of two media context conditions: News or Speech. Subjects were also assigned 
randomly to one of two social media order conditions: Social Media First (SM-First) or Social Media Last (SM-Last). Subjects in the SM-First/News-Context condition $(n=12)$ viewed the Facebook posts of both candidates for ten minutes and then viewed the three news articles for ten minutes. Subjects in the SM-First/Speech-Context condition $(n=11)$ viewed the Facebook posts of both candidates for ten minutes and then viewed the political speech for ten minutes. Subjects in the SM-Last/News-Context condition $(n=11)$ viewed the three news articles for ten minutes and then viewed the Facebook posts of both candidates for ten minutes. Subjects in the SM-Last/Speech-Context condition $(n=11)$ viewed the political speech for ten minutes and then viewed the Facebook posts of both candidates for ten minutes. It is important to note that subjects in the News Context conditions saw the same materials in both ordering conditions and also that subjects in the Speech Context conditions also saw the same materials in both ordering conditions. Thus, conclusions regarding order effects within these two content conditions are based on exposure to the same content.

The following dependent measures to assess knowledge and affect were collected at the end of the study phase

- Knowledge: Subjects were asked to indicate their "general knowledge level of the 2011 Mississippi governor's race" and to rate their knowledge about each candidate using the following scale: $1=$ "No knowledge," 2 = "Low knowledge," 3 = "Moderate knowledge," 4 = "High knowledge," $5=$ "Very high knowledge."

- Feeling thermometer: Subjects were asked to rate their feeling about each candidate on a "feeling thermometer" [90] where $1=$ "Cold" and $7=$ "Warm."

- Affect toward the candidates/ANES: Subjects were asked to rate the candidates on five affective terms: "angry," "hopeful," "afraid," "proud," and "anxious." The first four items on the checklist are used in the American National Election Studies, and "anxious" was added per Marcus et al. [44]. The checklist questions were in the form "When you think about <candidate name>, how <affect term $>$ does he make you feel?" The response scale was $1=$ "Not $<$ affect term $>$ at all," 2 = "Slightly $<$ affect term>," $3=$ "Moderately <affect term>," $4=$ "Very <affect term>," and $5=$ "Extremely $<$ affect term>."

- Liking of the candidates: Subjects were asked to "Please indicate how much you like/dislike this candidate" where 1 = "Dislike very much," 2 = "Dislike somewhat," 3 = "Neutral," 4 = "Like somewhat," and 5 = "Like very much."

- Likelihood of voting for the candidates: Subjects were asked to "Please indicate how likely it is that you would vote for this candidate" where 1 = "Definitely would not," 2 = "Probably would not," 3 $=$ "Neutral," $4=$ "Probably would," and $5=$ "Definitely would."

- Personal mood/PAD: The PAD scale is widely used to measure three dimensions of personal affect: Pleasure, Arousal, and Dominance [49]. We used a shortened version of the PAD measure consisting of 18 semantic differential scales and asked subjects to rate their mood. The word/phrase pairs on the scale are shown in Table 2. The first six measure the Pleasure dimension, the second six measure the Arousal dimension, and the final six measure the Dominance dimension. There were 7 points on each scale and the dependent measure for each of the three dimensions was the mean of the 6 scales for that dimension.

\subsection{Procedure}

After reading the consent form, each subject was instructed to "Imagine that you are about to move to Mississippi and that you want to decide which candidate to vote for when you get there." The subjects 
Table 2

Factor analysis of PAD scores

\begin{tabular}{lrcc}
\hline Scale & Factor 1 & Factor 2 & Factor 3 \\
\hline Happy-Unhappy & $\mathbf{0 . 8 8}$ & 0.11 & 0.07 \\
Pleased-Annoyed & $\mathbf{0 . 9 1}$ & 0.13 & 0.09 \\
Satisfied-Unsatisfied & $\mathbf{0 . 9 0}$ & 0.02 & 0.00 \\
Contented-Melancholic & $\mathbf{0 . 8 4}$ & 0.08 & 0.14 \\
Hopeful-Despairing & $\mathbf{0 . 7 9}$ & 0.25 & 0.11 \\
Relaxed-Bored & $\mathbf{0 . 7 1}$ & 0.34 & 0.39 \\
Stimulated-Relaxed & 0.08 & $\mathbf{0 . 7 9}$ & -0.07 \\
Excited-Calm & -0.02 & $\mathbf{0 . 7 0}$ & 0.23 \\
Frenzied-Sluggish & 0.09 & $\mathbf{0 . 8 3}$ & 0.09 \\
Jittery-Dull & 0.17 & $\mathbf{0 . 8 5}$ & 0.13 \\
Wide Awake-Sleepy & 0.30 & $\mathbf{0 . 7 8}$ & 0.05 \\
Aroused-Unaroused & 0.27 & $\mathbf{0 . 5 3}$ & 0.16 \\
Controlling-Controlled & 0.03 & 0.24 & $\mathbf{0 . 4 4}$ \\
Influential-Influenced & -0.08 & 0.45 & $\mathbf{0 . 6 2}$ \\
In Control-Cared For & 0.12 & 0.03 & $\mathbf{0 . 7 4}$ \\
Important-Awed & 0.56 & 0.14 & $\mathbf{0 . 5 1}$ \\
Dominant-Submissive & 0.35 & 0.08 & $\mathbf{0 . 7 1}$ \\
Autonomous-Guided & 0.09 & -0.08 & $\mathbf{0 . 7 5}$ \\
\hline
\end{tabular}

were instructed that they would be reading materials about the candidates and answering questions about their knowledge and mood.

The experiment was controlled entirely by a computer with all questions and materials appearing online. Each exposure period lasted for 10 minutes during which time subjects were free to read/browse any parts of the appropriate material that they wished. At the end of the entire session an informal, semi-structured interview lasting between 15-20 minutes was conducted by the experimenter(s).

\section{Results}

Missing data for any scale was replaced by the mean of the relevant scale regardless of condition across all subjects. Only six of the 37 measures contained missing values, with four missing only a single score. However, the feeling thermometer measure for each candidate was missing 10 scores distributed randomly across conditions.

With the exception of one factor analysis, all analyses in this section are $2 \times 2$ independent groups Analyses of Variance. The independent variables are Social Media Order (SM-First versus SM-Last), and Media Context (News versus Speech). When a two-way interaction was present, main effects are not described here.

\subsection{Mood/PAD factor analysis}

A factor analysis was conducted on the scores from the 18-scale PAD measure in order to verify the underlying assumption of Pleasure, Arousal, and Dominance factors. A 3-factor solution was forced and varimax rotation was used to evaluate the model. Together the first three components accounted for $64.4 \%$ of the variance in the scores. Table 2 shows the component loadings for all 18 scales. The loadings clearly identify the first 6 items as the strongest components of the Pleasure factor, the second six items as the strongest components of the Arousal factor, and the last 6 items as the strongest components of the Dominance factor. 


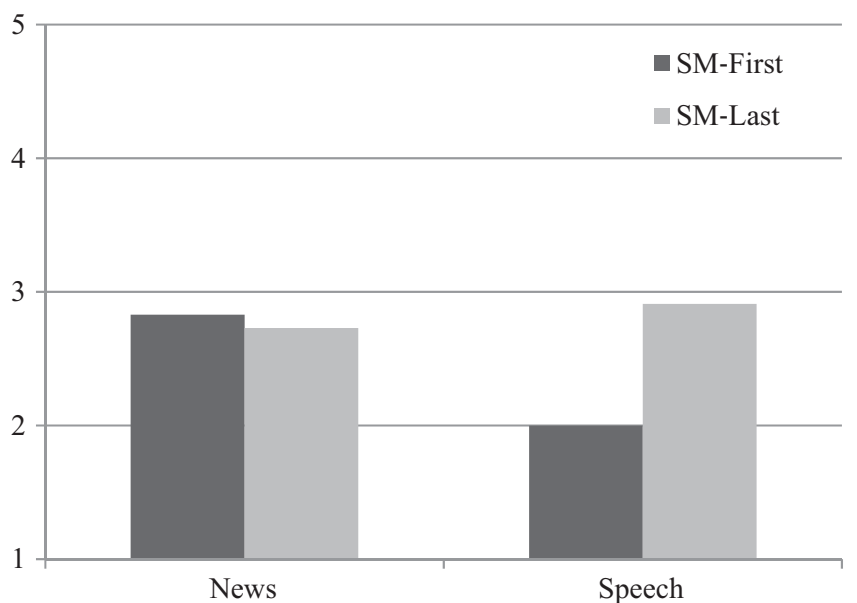

Fig. 2. Mean knowledge ratings $(1=$ low, $5=$ high $)$ in the News and Speech conditions when social media was seen first (SM-First) and last (SM-Last).

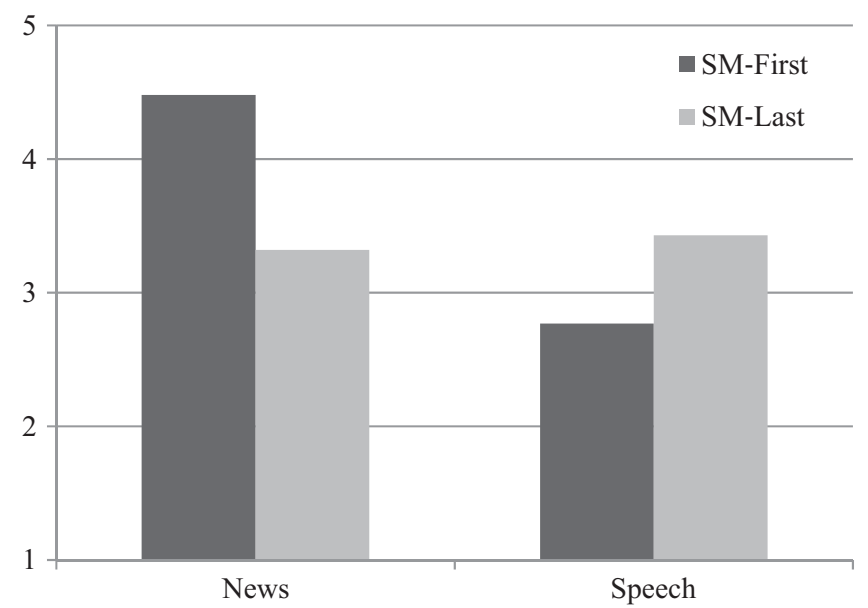

Fig. 3. Mean feeling thermometer ratings for Phil Bryant $(1=$ Cold, $5=$ Warm $)$ in the News and Speech conditions when social media was seen first (SM-First) and last (SM-Last).

\subsection{Knowledge}

Participants' knowledge about the gubernatorial race depended both on what material they were exposed to and what order. There was an interaction between Context and Social Media Order, $F(1,41)$ $=4.79, p<0.03$. As Fig. 2 shows, subjects who read news and social media did not differ on their perceived knowledge level when the order was changed, but subjects who read the speech and social media felt that they knew less when the social media came first than when it came last.

With regard to knowledge about the candidates, there were no effects for knowledge about Phil Bryant, but there was a main effect of Context for Johnny Dupree such that people who read social media and news felt that they knew more about Dupree than people who read social media and the speech (mean knowledge ratings $=2.78$ and 2.27 , respectively), $F(1,41)=2.89, p<0.007$. 


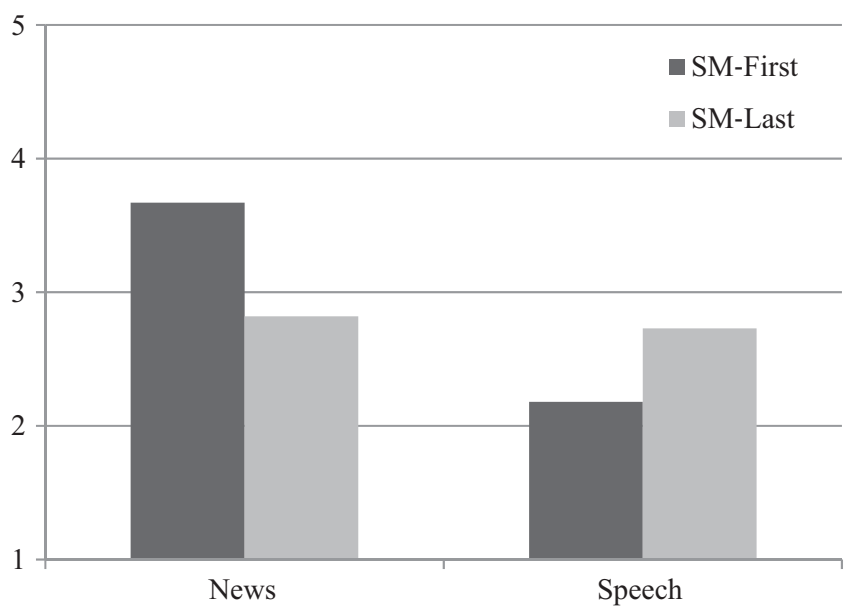

Fig. 4. Mean liking ratings for Phil Bryant $(1=$ Dislike Very Much, $5=$ Like Very Much $)$ in the News and Speech conditions when social media was seen first (SM-First) and last (SM-Last).

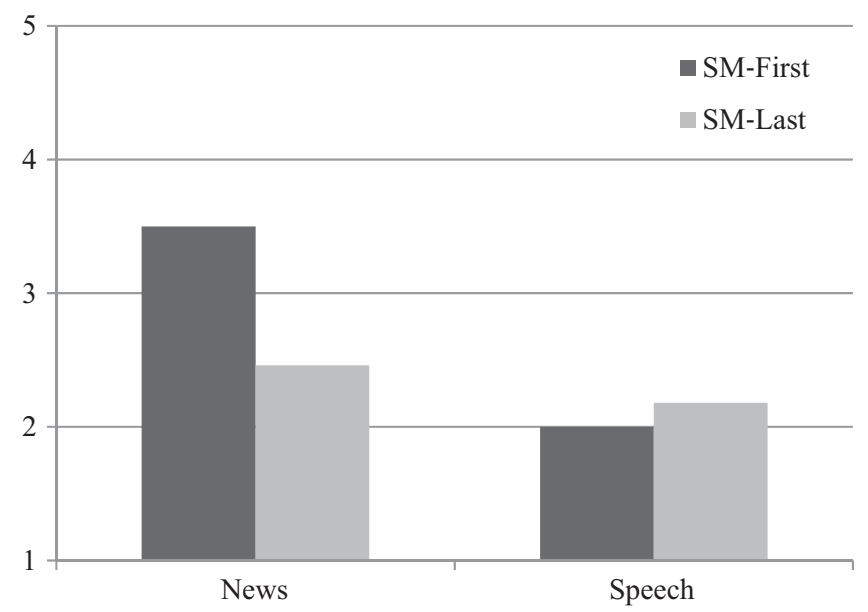

Fig. 5. Mean likelihood of voting for Phil Bryant $(1=$ Definitely Would Not, $5=$ Definitely Would $)$ in the News and Speech conditions when social media was seen first (SM-First) and last (SM-Last).

\subsection{Feeling thermometer, liking, and likelihood of voting}

The feeling thermometer, liking, and likelihood of voting measures all assess attitude toward the political candidates. Their behavior was different between the two candidates but consistent for each candidate. In general, Phil Bryant's measures interacted with social media order whereas Johnny DuPree's did not. For Phil Bryant there was an interaction between Context and Social Media Order for the temperature measure (Fig. 3), $F(1,41)=7.12, p<0.01$, for the liking score (Fig. 4), $F(1,41)=8.57, p<0.01$, and for the likelihood of voting score (Fig. 5), $F(1,41)=4.90, p<0.03$. Subjects gave Bryant a warmer temperature rating, liked him better, and were more likely to vote for him when they encountered social media followed by news. In the speech context, social media order either didn't matter or went the other way.

Social media order didn't matter for Dupree, however subjects felt colder towards him and were less 


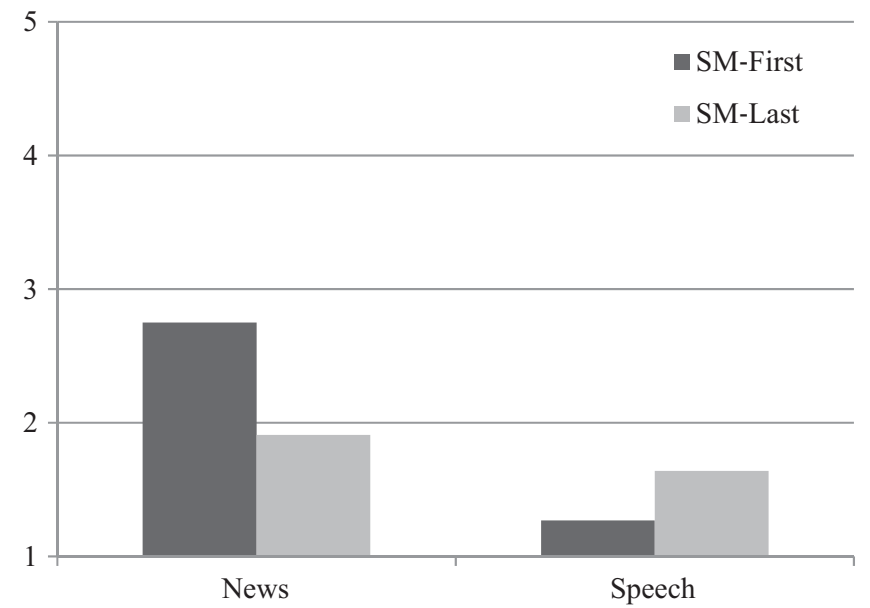

Fig. 6. Mean Hopefulness ratings for Phil Bryant $(1=$ Not Hopeful, 5 = Extremely Hopeful $)$ in the News and Speech conditions when social media was seen first (SM-First) and last (SM-Last).

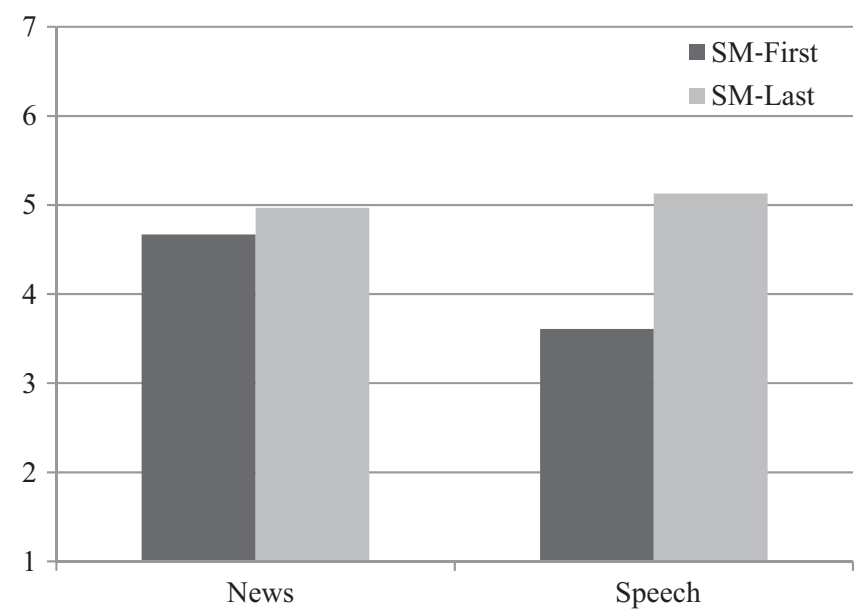

Fig. 7. Mean Pleasure ratings $(1=$ Low, $7=$ High $)$ across candidates in the News and Speech conditions when social media was seen first (SM-First) and last (SM-Last).

likely to vote for him in the news context than in the speech context. The mean temperature ratings were 4.05 and 4.66 in the News and Speech contexts respectively, $F(1,41)=4.39, p<0.04$, and the mean voting likelihood ratings were 3.0 and 3.55 in the News and Speech contexts respectively, $F(1,41)=$ $4.35, p<0.04$.

\subsection{ANES}

Consistent with the thermometer, liking, and likelihood of voting measures, the ANES measure regarding Hopefulness also showed an interaction between Context and Social Media Order for Bryant but not for Dupree. Specifically, subjects felt more hopeful about Bryant in the News context, especially when they encountered social media first (Fig. 6), $F(1,41)=4.93, p<0.03$. Subjects also felt more proud about Bryant in the News context than in the Speech context (means $=1.99$ versus 1.41 for News 


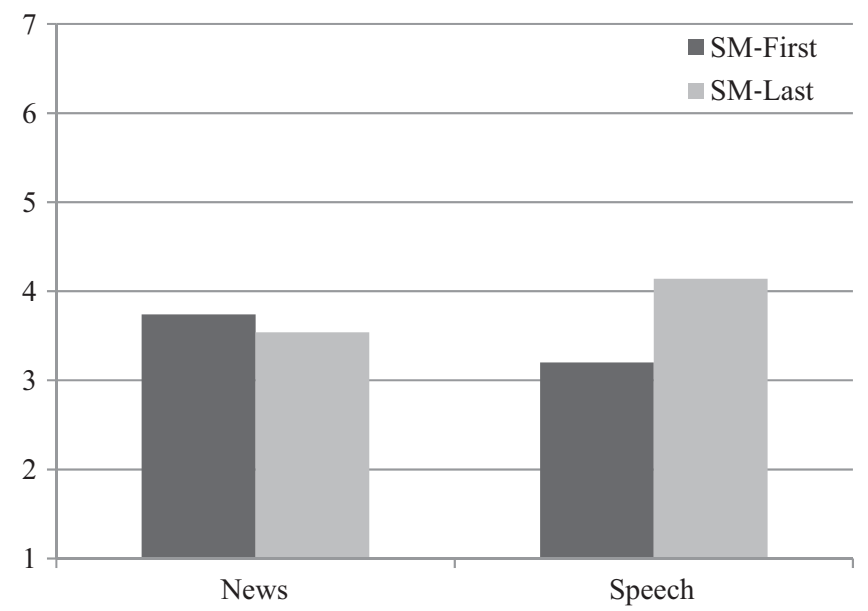

Fig. 8. Mean Arousal ratings $(1=$ Low, $7=$ High $)$ across candidates in the News and Speech conditions when social media was seen first (SM-First) and last (SM-Last).

and Speech respectively), $F(1,41)=4.06, p<0.05$, although this did not interact with Social Media Order. The negative ANES scales (Angry, Afraid, and Anxious) showed no effects and there were no effects of the ANES scales for Dupree.

\section{5. $P A D$}

Both the Pleasure and Arousal dimensions of the PAD scale showed interactions between Context and Social Media Order (Figs 7 and 8, which show inverted scales so that higher arousal and pleasure ratings are larger numbers). There was a difference in arousal and pleasure in the Speech condition only such that subjects had higher arousal ratings and higher pleasure ratings when social media came last compared to when it came first, $F(1,41)=5.05, p<0.03$ for Pleasure, and $F(1,41)=4.41, p<0.04$ for Arousal.

There was a main effect of the Social Media Order condition on the Dominance dimension of the PAD scale, $F(1,41)=6.28, p<0.02$, with subjects who saw social media first reporting feeling less dominant than subjects who saw social media last (inverted scale means $=3.97$ and 4.59 respectively).

\section{Discussion}

\subsection{Overview}

We studied people as they browsed information about competing politicians across mixed media types, focusing in particular on social media mixed with traditional online news. This type of browsing is increasingly characteristic of the online browsing behavior of news consumers $[6,7,29,33,46]$. Liberal inter-linkage among media types encourages news consumers to cross application boundaries, and so we asked whether it matters in what order people encounter various media. We found that social media interacts in complex ways to influence perceived knowledge, feelings towards political candidates and likelihood of voting for a candidate, and personal feelings. Thus we suggest that social media is not a trivial factor in political impression formation and decision making.

Specifically, we found the following interactions when social media and news articles were mixed: 
- Higher temperature rating for Phil Bryant when social media was first

- Higher liking score for Phil Bryant Bryant when social media was first

- Higher feeling of hopefulness when thinking about Phil Bryant when social media was first

- Higher likelihood of voting for Phil Bryant Bryant when social media was first

We also observed the following when social media and the irrelevant speech were mixed:

- Lower perceived general knowledge of the race when social media was first

- Lower temperature rating for Phil Bryant when social media was first

- Lower liking score for Phil Bryant when social media was first

- Lower feeling of hopefulness about Phil Bryant when social media was first

- Lower pleasure rating when social media was first

- Lower level of arousal when social media was first

Research question 1 asked if social media order influenced perceived knowledge. Knowledge was influenced by the order of social media with other media, however social media order was not important in the condition when subjects actually learned about the candidates from news articles. Because we did not observe order effects in the News conditions, we do not have a conclusion concerning the inquiry amplification or inquiry suppression effects.

Instead, subjects felt that they were less informed when they saw social media together with the political speech (they were actually less informed in this condition) and they felt this more strongly when social media came first. We did observe that the speech was not as uninformative as we intended. Subjects tried to make it relevant to the election even though it had nothing to do with the election. One subject explained:

"From what I read, it was the former governor's speech. By reading the speech I was able to find what the state needs and, based on that information, I could decide."

Thus, we should probably consider the speech to be "contextually informative," if not directly informative about the candidates' positions.

One explanation for our social media order effect on knowledge in the Speech condition could be that subjects generated questions and expectations from the social media materials which they then found unanswerable by the irrelevant speech. In other words, the speech, when it came at the end of the experiment was a letdown. One subject explained that "Facebook was much easier and fun to read" and that the speech was "a downer."

Research question 2 asked if social media order influenced feelings about the candidates. We found several effects of social media order in the News context condition, all of which consistently showed greater favorability towards one candidate when social media came first. These feelings even led to a higher likelihood of voting for the candidate when social media came first. These results are consistent with the affect amplification effect, that social media creates feelings towards the candidates that are then amplified by subsequent informative material.

Unexpectedly we also found order effects in the Speech condition, and they were opposite to the News condition. If we consider the speech to be "contextually relevant," then the "letdown" explanation discussed in the knowledge section above may also apply to feelings about the candidates.

Research question 3 asked if social media order influenced personal feelings. Personal pleasure and arousal were influenced by social media order, answering RQ3 in the affirmative. However, like the knowledge measure, we found no effects in the News condition and can therefore not comment on the personal affect amplification or depression effects as we intended. But, we did observe lowered pleasure and arousal scores in the Speech condition when social media came first. Again, if we consider the 
speech to be "contextually relevant," then we may have evidence for a personal affect depression effect when the expectations generated by exposure to social media are not realized by subsequent materials.

\subsection{Motivated reasoning and the network society}

Social media content influences both cognitive processes and affective processes and will therefore be relevant to any motivated reasoning theory of political decision making [34,58,60,61]. The contemporary media environment is characterized by extreme type hybridity, dense interconnection, and an "always on" functionality. Papacharissi [53] describes contemporary, digitally-engaged citizens as being "liquid" and "reflexive" as they navigate multiple information spaces, stressing the "monitorial" stance toward information in contrast to a more deliberative stance. Together these characteristics make "on-line" schema-update models of impression formation [37,41,60], in which affect and cognition are intermingled and satisficing is necessary, more important than ever.

Papacharissi's [52] general claim that "affective news" is a new kind of media environment in which information and emotion intermingle to generate "affective attunement" and create "affective publics" is substantiated in this research. However, we have demonstrated that the order in which hybrid information is encountered matters.

In the political domain studied here, the strongest effects were observed on feelings toward a political candidate when social media was encountered before news. This is consistent with Rahm's research showing that cues about whether news is important are taken from a sense of the "public mood" [58]. The effect was consistent with multistep flow models of media influence since the social media content provided an opinion frame through which news about the candidates was filtered $[7,8,51,88]$. This effect did not really generalize to influence the mood of the participants or their perceived knowledge, however.

Unexpectedly, when social media was encountered before an irrelevant political speech, there were negative impacts on participant knowledge, feelings toward the candidates, and personal mood. What we considered to be the "irrelevant" condition may in fact be more like the hybrid news environment than we intended, since the new media environment mixes news and personal content in an almost random fashion. This leaves news consumers to sort out for themselves what is related to what, including how to apply emotional states generated by affective content to more dispassionate material, related or not. To the degree that "affective attunement" [52] and motivated reasoning are taking place continuously, affective expectations will seek targets in surrounding news content. Our research suggests that in the context of political dialog, not finding appropriate attachments for affective interpretation (which should be more common in disorganized, hybrid information spaces) may be frustrating and lead to negative impacts on confidence about topic knowledge, feelings toward the political candidates, and personal feelings.

\subsection{Limitations and future research}

Many of the limitations of this study come from the fact that we utilized real materials from social media and news and did not alter them in any way. On the one hand, we forfeited control over several factors that might be relevant to online political information browsing, but on the other hand we increased the ecological validity of the study by offering participants a more naturalistic media browsing environment. We argue that at this early stage of investigation ecological validity trumps experimental control so long as we can use the questions raised to inform future hypotheses.

This study utilized a small number of media materials in a single political race. This limits the generalizability of the findings beyond these materials and makes outcomes that might be due to the peculiarities 
of these particular materials more salient. We acknowledge that provocative content in one candidate's Facebook content led to behavior that might not be characteristic of all social media encounters (it was not characteristic even in the other candidate's data), however we also argue that this provided a unique opportunity to see how affectively charged social media materials interacted with other information. While affective content is discouraged and systematically eliminated from traditional news, it is common in social media. Political decision-making models in which affect and cognition combine to create impressions about candidates are more important than ever in contemporary mixed-media environments. In future studies, the affective impact of social media materials should be varied systematically to study this phenomenon.

We also utilized a relatively small number of participants who were homogeneous with regard to age and background. This limits the generalizability of our results to college-age students, however this group is the most immersed in the contemporary hybrid media environment and hence the most relevant to the findings of this study.

Social media is image-heavy, and we observed that participants paid especially close attention to pictures of candidates and made judgments about candidates' community engagement from the pictures they saw of candidates interacting with constituents at campaign events. Since these images were not systematically varied, our sample of images in the social media materials was likely narrower in topic scope than would be natural. Future studies should assess the categories of images that social media readers find relevant to political impression formation and vary them systematically in mixed-media situations to better understand their role.

While we used real materials sampled from the universe of Facebook posts and online news articles available on the two candidates studied, we did limit the subjects to considering these materials alone. In real life, social media is part of a mix of information sources that are interweaved both by serendipity and by strategy. Increasingly, people have more control over their sources of information and they have a greater ability to shape them. Semaan et al. [74] studied how people dynamically shape their information environments to best serve their browsing and learning goals, and their research revealed that people utilize a wide range of social media and other socially-enabled information sources. In future research, we intend to look more closely at the browsing behavior of individuals as they study a variety of information sources and make their own independent choices about what to read or contribute.

Reading what others have to say is only one part of the social media experience. An important additional component for many people is the ability to participate by posting their own comments, and research suggests that active participation in social media changes the experience and even the voting behavior of people as they learn about politicians [45]. In future studies, the order effects of participation across media should be examined in the same way that the order effects of browsing across media were explored in this study.

\section{Conclusion}

Facebook was founded in 2004 and Twitter in 2006. Other social media environments, which are being used with ever increasing frequency [14], were founded even more recently. Almost all online news stories are now accompanied by a comment section, and most social media sites have many direct links to major news outlets. In terms of politics, the 2008 U.S. presidential election of Barack Obama is considered to be the first to utilize social media extensively. In other words, the networked civic environment that most of us now inhabit has developed in only the last ten years. Unlike the contained public sphere concept of Habermas (both physical and virtual), the overlapping public and private spheres of 
the new networked civic environment $[53,54]$ are easily traversed, and they engage a range of both rational and emotional processes. In the hybrid media environment now dominant for most people, especially young people, encountering "cool" and objective content alongside and intertwined with "hot" opinion and more passionate personal reflections is commonplace. We now make political decisions as part of the technology-enabled "affective public" described by Papacharissi [52]. The research questions in this space should now move to how diverse information sources and opportunities for participation interact. Here we recognize that different types of information influence both affect and cognition, and that different mixtures of information types result in different emotional and rational experiences. The manner in which people mix media when browsing increasingly complex online public and private spheres $[10,53,57]$ and how this influences their decision making processes are issues ripe for future research.

\section{Acknowledgements}

This research was funded by NSF award No. IIS-1064852 to the first author. Any opinions, findings and conclusions or recommendations expressed in this material are those of the authors and do not necessarily reflect the views of the National Science Foundation.

\section{Note}

A subset of preliminary data from his study was discussed in Robertson et al. [67]. This paper includes more subjects, more conditions, extended results, and expanded discussion.

\section{References}

[1] W.L. Bennett and J.B. Manheim, The one-step flow of communication, Annals of the American Academy of Political and Social Science 608(1) (2006), 213-232.

[2] J.A. Berger and K.L. Milkman, What makes online content viral? Journal of Marketing Research 49(2) (2012), $192-205$.

[3] B. Bimber and R. Davis, Campaigning online: The Internet in U.S. elections, Oxford University Press: Oxford, 2003.

[4] J. Bollen, H. Mao and A. Pepe, Modeling public mood and emotion: Twitter sentiment and socio-economic phenomena. In Proceedings of the Fifth International AAAI Conference on Weblogs and Social Media, Association for the Advancement of Artificial Intelligence, 2011, pp. 450-453.

[5] J. Bollen, H. Mao and X.-J. Zeng, Twitter mood predicts the stock market, Journal of Computational Science 2(1) (2011), 1-8. doi: 10.1016/j.jocs.2010.12.007.

[6] A. Chadwick, The political information cycle in a hybrid news system: The British prime minister and the "Bullygate" affair, The International Journal of Press/Politics 16(1) (2011), 3-29.

[7] A. Chadwick, Web 2.0: New challenges for the study of e-democracy in an era of informational exuberance, I/S: $A$ Journal of Law and Policy for the Information Society 5(1) (2009), 9-41.

[8] S.H. Chaffee, Mass media and interpersonal channels: Competitive, convergent, or complementary? In Inter/media: Interpersonal communication in a media world, G. Gumpert and R. Cathart, eds., Oxford University Press: New York, 1986. pp. 57-77.

[9] S. Choi, The two-step flow of communication in Twitter-based public forums, Social Science Computer Review 33(6) (2015), 696-711. doi: 10.1177/0894439314556599.

[10] L. Dahlberg, Computer-mediated communication and the public sphere: A critical analysis, Journal of ComputerMediated Communication 7(1) (2001). doi: 10.1111/j.1083-6101.2001.tb00137.x.

[11] P. Dahlgren, The Internet, public spheres, and political communication: Dispersion and deliberation, Political Communication 22(2) (2005), 147-162.

[12] U.M. Dholakia, R.P. Bagozzi and L.K. Pearo, A social influence model of consumer participation in network- and smallgroup-based virtual communities, International Journal of Research in Marketing 21(3) (2004), 241-263. 
[13] J. Donath and D. boyd, Public displays of connection, BT Technology Journal 22(4) (2004), 71-82.

[14] M. Duggan, N.B. Ellison, C. Lampe, A. Lenhart and M. Madden, Social media update 2014, Pew Research Center, January 2015. Available at: http://www.pewinternet.org/2015/01/09/social-media-update-2014/.

[15] N.B. Ellison, C. Steinfield and C. Lampe, The benefits of Facebook "friends": Social capital and college students' use of online social network sites, Journal of Computer-Mediated Communication 12(4) (2007), 1143-1168. doi: 10.1111/ j.1083-6101.2007.00367.x.

[16] N. Fraser, Rethinking the public sphere: A contribution to the critique of actually existing democracy. In Habermas and the Public Sphere, C. Calhoun, ed., MIT Press: Cambridge MA, 1992, pp. 109-142.

[17] K. Gibson and S. O'Donnell, User-generated video and the online public sphere: Will YouTube facilitate digital freedom of expression in Atlantic Canada? American Communication Journal 10(3) (2008). Available at: http://ac-journal.org/ journal/pubs/2008/Fall\%2008\%20-\%20Defining\%20Digital\%20Freedom/Article_5.pdf, Accessed on March 26, 2014.

[18] E. Gilbert, T. Bergstrom and K. Karahalios, Blogs are echo chambers: Blogs are echo chambers, Proceedings of the 42nd Hawaii International Conference on System Sciences, (HICSS '09) (2009). doi: 10.1109/HICSS.2009.91.

[19] H. Gil de Zúñiga, N. Jung, S. Valenzuela, Social media use for news and individuals' social capital, civic engagement and political participation, Journal of Computer Mediated Communication 17 (2012), 319-336.

[20] J. Glaser and P. Salovey, Affect in electoral politics, Personality and Social Psychology Review 2(3) (1998), 156-172.

[21] J. Habermas, The structural transformation of the public sphere: An inquiry into a category of bourgeois society, MIT Press: Cambridge MA, 1989.

[22] K.N. Hampton, L.S. Goulet, L. Raine and K. Purcell, Social networking sites and our lives. Pew Internet and American Life Project, June 16, 2011. http://pewinternet.org/Reports/2011/Technology-and-social-networks.aspx, Accessed on June. 14, 2012.

[23] K. Hampton and B. Wellman, Neighboring in Netville: How the Internet supports community and social capital in a wired suburb, City \& Community 2(4) (2003), 277-311.

[24] R. Hastie, A primer of information-processing theory for the political scientist. In Political Cognition: The 19th Annual Carnegie Symposium on Cognition, R.R. Lau and D.O. Sears, eds., Erlbaum, Hillsdale, NJ, 1986, pp. 11-39.

[25] M. Hilbert, J. Vasquez, D. Halpern, S. Valenzuela and E. Arriagada, One step, two step, network step? Complementary perspectives on communication flows in Twittered citizen protests, Social Science Computer Review, April 12, (2016). doi: $10.1177 / 0894439316639561$.

[26] T.A. Hoang, W.W. Cohen, E.P. Lim, D. Pierce and D. Redlawsk, Politics, sharing and emotion in microblogs. In Proceedings of the 2013 IEEE/ACM International Conference on Advances in Social Networks Analysis and Mining, ACM Press, pp. 282-289.

[27] J. Holcomb, J. Gottfried and A. Mitchell, News use across social media platforms. Pew Research Center, November, 2013. Available at http://www.journalism.org/2013/11/14/news-use-across-social-media-platforms/, Accessed on March 7, 2014.

[28] J. Horrigan, K. Garrett and P. Resnick, The Internet and democratic debate. Pew Research Center, October, 2004. Available at http://www.pewinternet.org/2004/10/27/the-internet-and-democratic-debate/, Accessed on March 7, 2014.

[29] P.N. Howard and A. Chadwick, Conclusion: Political omnivores and wired states. In The handbook of internet politics, A. Chadwick and P.N. Howard, eds., Routledge: London, 2009, pp. 424-434.

[30] B.D. Jones, Bounded rationality, Annual Review of Political Science 2 (1999), 297-321.

[31] E. Katz and P.F. Lazarsfeld, Personal influence: The part played by people in the flow of mass communications, The Free Press: New York, 1955.

[32] A. Kavanaugh, J.M. Carroll, M.B. Rosson, T.T. Zin and D.D. Reese, Community networks: Where offline communities meet online, Journal of Computer-Mediated Communication 10(4) (2005). doi: 10.1111/j.1083-6101.2005.tb00266.x.

[33] U. Klinger and J. Svensson, The emergence of network media logic in political communication: A theoretical approach, New Media and Society 17 (2015), 1241-1257. doi: 10.1177/1461444814522952.

[34] Z. Kunda, Motivated inference: Self-serving generation and evaluation of causal theories, Journal of Personality and Social Psychology 53(4) (1987), 636-647.

[35] C. Lampe, N. Ellison and C. Steinfield, A face (book) in the crowd: Social searching vs. social browsing. In Proceedings of the 20th Anniversary Conference on Computer Supported Cooperative Work, ACM: New York, 2006, 167-170.

[36] C. Lampe, R. Wash, A. Valesquez and E. Ozkaya, Motivations to participate in online communities. In Proceedings of the SIGCHI Conference on Human Factors in Computing Systems (CHI'10), ACM: New York, 2010, pp. 1927-1936.

[37] R. Lau, Models of decision making. In D. Sears, L. Huddy and R. Jervis, Oxford handbook of political psychology, Oxford University Press: Oxford, 2003.

[38] C.S. Lee and L. Ma, News sharing in social media: The effect of gratifications and prior experience, Computers in Human Behavior 28(2) (2012), 331-339.

[39] B. Loader and D. Mercea, Networking democracy? Social media innovations and participatory politics, Information, Communication \& Society 14(6) (2011), 757-769. 
[40] M. Lodge, K. McGraw and P. Stroh, An impression-driven model of candidate evaluation, American Political Science Review 83(June) (1989), 399-419.

[41] M. Lodge, M. Steenbergen and S. Brau, The responsive voter: Campaign information and the dynamics of candidate evaluation, American Political Science Review 89(June) (1995), 309-326.

[42] M. Lodge and C. Taber, Three steps toward a theory of motivated political reasoning. In Elements of reason: Cognition, choice, and the bounds of rationality, A. Lupia, M.D. McCubbins and S.L. Popkin, eds., Cambridge University Press: London, 2000, pp. 183-213.

[43] G.E. Marcus, Emotions in politics, Annual Review of Political Science 3 (2000), 221-250.

[44] G.E. Marcus, W.R. Neuman and M. MacKuen, Affective intelligence and political judgment, University of Chicago Press: Chicago, 2000.

[45] M. Maruyama, S.P. Robertson, S. Douglas and B. Semaan, Hybrid media consumption: How tweeting during a televised political debate influences the vote decision. In Proceedings of the 17th ACM Conference on Computer Supported Cooperative Work, ACM: New York, 2014, pp. 1422-1432.

[46] M. Messner and M.W. Distaso, The source cycle: How traditional media and weblogs use each other as sources, Journalism Studies 9(3) (2008), 447-463.

[47] A. Mitchell, J. Kiley, J. Gottfried and E. Guskin, The role of news on Facebook: Common yet incidental. Pew Research, 2013. Available at http://www.journalism.org/2013/10/24/the-role-of-news-on-facebook/, Accessed on March 7, 2014.

[48] M. McComb and S.I. Ghanem, The convergence of agenda setting and framing. In S.D. Reese, O.H.J. Gandy, and A.E. Grant, eds., Framing public life: Perspectives on media and our understanding of the social world, Erlbaum: Mahwah, NJ, 2003, pp. 67-82.

[49] A. Mehrabian, Pleasure-arousal-dominance: A general framework for describing and measuring individual differenced in temperament, Current Psychology 14(4) (1996), 261-292.

[50] M. Milliken and S. O'Donnell, User-generated online video: The next public sphere? IEEE International Symposium on Technology and Society, 2008, pp. 1-3.

[51] P. Norris and J. Curtice, Getting the message out: A two-step model of the role of the Internet in campaign communication flows during the 2005 British general election, Journal of Information Technology \& Politics 4(4) (2008), 3-13. doi: $10.1080 / 19331680801975359$.

[52] Z. Papacharissi, Affective publics: Sentiment, technology, and politics, Oxford University Press, 2015.

[53] Z. Papacharissi, A private sphere: Democracy in a digital age, Polity Press: Cambridge, 2010.

[54] Z. Papacharissi, The virtual sphere: The Internet as a public sphere, New Media and Society 4(1) (2002), 9-27.

[55] Z. Papacharissi and M. de Fatima Olivera, Affective news and networked publics: The rhythms of news storytelling on \#Egypt, Journal of Communication 62(2) (2012), 266-282.

[56] N. Park, K.F. Kee and S. Valenzuela, Is there social capital in a social network site?: Facebook use and college students' life satisfaction, trust, and participation, Journal of Computer-Mediated Communication 14(4) (2009), 875-901.

[57] N. Poor, Mechanisms of an online public sphere: The website Slashdot, Journal of Computer-Mediated Communication 10(2) (2005). doi: 10.1111/j.1083-6101.2005.tb00241.x.

[58] W.M. Rahn, Affect as information: The role of public mood in political reasoning. In Elements of reason: Cognition, choice, and the bounds of rationality, A. Lupia, M.D. McCubbins, and S.L. Popkin, eds., Cambridge University Press: London, 2000, pp. 130-151.

[59] L. Raine and A. Smith, Politics on social networking sites, Pew Internet and American Life Project, Sept. 4, 2012. http://pewinternet.org/Reports/2012/Politics-on-SNS.aspx.

[60] D.P. Redlawsk, Hot cognition or cool consideration? Testing the effects of motivated reasoning on political decision making, The Journal of Politics 64(4) (2002), 1021-1044.

[61] D.P. Redlawsk, Motivated reasoning, affect, and the role of memory in voter decision-making. In Feeling politics: Emotion in political information processing, D.P Redlawsk, ed., Palgrave Macmillan: New York, 2006, pp. 87-107.

[62] D.P. Redlawsk, You must remember this: A test of the on-line model of voting, The Journal of Politics 63(1) (2001), 29-58.

[63] P. Resnick, Beyond bowling together: Sociotechnical capital. In J. Carroll, ed., HCI in the new millennium, AddisonWesley: Boston, MA, 2001, pp. 247-272.

[64] W.H. Riker and P.C. Ordeshook, A theory of the calculus of voting, American Political Science Review 62(March) (1968), 25-42.

[65] S.P. Robertson, Changes in referents and emotions over time in election-related social networking dialog. In Proceedings of the 44th Annual Meeting of the Hawaii International Conference on Systems Sciences, IEEE Computer Society: Washington DC, 2011, pp. 9.

[66] S.P. Robertson, S. Douglas, M. Maruyama and L. Chen, Political dialog evolution in a social network. In Proceedings of the 13th Annual International Conference on Digital Government Research, ACM: New York, 2012, pp. 40-48.

[67] S.P. Robertson, B. Semaan, S. Douglas and M. Maruyama, Mixed media: Interactions of social and traditional media in 
political decision making. In Proceedings of the 46th Annual Meeting of the Hawaii International Conference on System Sciences, IEEE Computer Society: Washington, DC, 2013, pp. 2013-2022.

[68] S.P. Robertson, R.K. Vatrapu and R. Medina, The social life of social networks: Facebook linkage patterns in the 2008 U.S. presidential election. In Proceedings of the 10th Annual International Conference on Digital Government Research, Digital Government Society of North America, 2009, pp. 6-15.

[69] S.P. Robertson, R.K. Vatrapu and R. Medina, Off-the-wall political discourse: Facebook use in the 2008 U.S. presidential election, Information Polity 15(1-2) (2010), 11-31.

[70] S.P. Robertson, R.K. Vatrapu and R. Medina, Online video "friends" social networking: Overlapping online public spheres in the 2008 U.S. presidential election, Journal of Information Technology and Politics 7(2-3) (2010), 182-201.

[71] T. Scheafer, How to evaluate it: The role of story-evaluative tone in agenda setting and priming, Journal of Communication 57(1) (2006), 21-39.

[72] D.A. Scheufele and D. Tewksbury, Framing, agenda setting, and priming: The evolution of three media effects models, Journal of Communication 57(1) (2007), 9-20.

[73] K. Schoenbach and H. Semeetko, Agenda-setting, agenda-reinforcing, or agenda-deflating: A study of the 1990 German national election, Journalism Quarterly 69 (1992), 837-846.

[74] B. Semaan, S.P. Robertson, S. Douglas and M. Maruyama, Social media supporting political deliberation across multiple public spheres: Towards depolarization. In Proceedings of the 17th ACM Conference on Computer Supported Cooperative Work, ACM: New York, NY, 2014, pp. 1409-1421.

[75] H.A. Simon, Information processing models of cognition, Annual Review of Psychology 30 (1979), 363-396.

[76] H.A. Simon, Human nature in politics: The dialogue of psychology with political science, American Political Science Review 79(June) (1985), 293-304.

[77] H.A. Simon, Rationality in political behavior, Political Psychology 16(March) (1995), 45-61.

[78] S. Stieglitz and L. Dang-Xuan, Emotions and information diffusion in social media - sentiment of microblogs and sharing behavior, Journal of Management Information Systems 29(4) (2013), 217-248.

[79] J. Stromer-Galley, Diversity of political conversation on the Internet: Users' perspectives, Journal of Computer-Mediated Communication 8(3) (2003). doi: 10.1111/j.1083-6101.2003.tb00215.x.

[80] N.J. Stroud, Media effects, selective exposure, and Fahrenheit 9/11, Political Communication 24(4) (2007), 415-432.

[81] N.J. Stroud, Media use and political predispositions: Revisiting the concept of selective exposure, Political Behavior 30 (2008), 341-366.

[82] J.B. Thompson, The media and modernity: A social theory of the media, Polity Press: Cambridge, 1995.

[83] M. Tremayne, Blogging, citizenship, and the future of media, Routledge, Taylor \& Francis Group: New York, 2006.

[84] A. Tumasjan, T.O. Sprenger, P.G. Sandner, I.M. Welpe, Predicting elections with Twitter: What 140 characters reveal about political sentiment. In Proceedings of the Fourth International AAAI Conference on Weblogs and Social Media, Association for the Advancement of Artificial Intelligence, 2010, pp. 178-185.

[85] C. Vaccari, A. Chadwick and B. O'Loughlin, Dual screening the political: Media events, social media, and citizen engagement, Journal of Communication 65(6) (2015), 1041-1061.

[86] R. Vatrapu, S.P. Robertson and W. Dissanayake, Are political weblogs public spheres or partisan spheres? International Reports on Socio-Informatics 5(1) (2008), 7-26.

[87] K. Wallsten, Many sources, one message: Political blog links to online videos during the 2008 campaign, Journal of Political Marketing 10(1-2) (2011), 88-114.

[88] J.B. Walther, C.T. Carr, S.S.W Choi, D.C. DeAndrea, J. Kim, S.T. Tong, B. Van Der Heide, Interaction of interpersonal, peer, and media influence sources online. In A networked self: Identity, community, and culture on social network sites, Z. Papacharissi, ed., Routledge: New York, 2011, pp. 17-38.

[89] B.E. Weeks, A. Ardèvol-Abreu and H. Gil de Zúñiga, Online influence? Social media use, opinion leadership, and political persuasion, International Journal of Opinion Research (2015). doi: 10.1093/ijpor/edv050.

[90] H.F. Weisberg and J.G. Rusk, Dimensions of candidate evaluation, American Political Science Review 64 (1970), 11671185.

[91] B. Wellman, A.Q. Haase, J. Witte and K. Hampton, Does the Internet increase, decrease, or supplement social capital? Social networks, participation, and community commitment, American Behavioral Scientist 45(3) (2001), 436-455.

[92] R.H. Wicks, A. Bradley, G. Blackburn and T. Fields, Tracking the blogs: An evaluation of attacks, acclaims, and rebuttals presented on political blogs during the 2008 presidential election, American Behavioral Scientist 55 (2011), 651-666.

[93] B. Williams and G. Gulati, The political impact of Facebook: Evidence from the 2006 midterm elections and 2008 nomination contest, Politics and Technology Review 1 (2008), 11-21.

[94] W. Wirth and H. Schramm, Media and emotions, Communication Research Trends 24(3) (2005), 3-39. 